\title{
Train-the-Trainer Course on Energy Efficient Operation of Ships
}

\author{
Raphaël Baumler, Aykut I. Ölçer*, Anne Pazaver, Takeshi Nakazawa, \\ Michael Baldauf, Daniel Moon, Clive Cole \\ World Maritime University (WMU), Malmö, Sweden \\ Email: aio@wmu.se
}

Received 24 September 2014; revised 21 October 2014; accepted 16 November 2014

Copyright (C) 2014 by authors and Scientific Research Publishing Inc.

This work is licensed under the Creative Commons Attribution International License (CC BY). http://creativecommons.org/licenses/by/4.0/

c) (i) Open Access

\begin{abstract}
The International Maritime Organization (IMO) expanded, in 2011, its air emissions control regulations by encouraging energy efficiency and added them to MARPOL Annex VI. To assist national implementation of these new regulations, the IMO-KOICA partnership sponsored the development of a Train-the-Trainer (TTT) project on energy efficient operation of ships. The first project objective was to develop a comprehensive training package, which covers company policy and shipping contracts, port/ship interaction, ship technical solutions and day-to-day ship management. The second objective was to enhance capacity building in developing countries by creating a pool of instructors able to raise awareness in their respective regions using the dedicated training material. During each session, pedagogic support tools backed the content delivery. Forty-one participants from thirty-two countries attended two sessions of the TTT course. The TTT training formula, blending content and pedagogics, demonstrated its efficiency by committing and challenging each participant during the entire course. The outcome of the final day assessment showed that participants captured the essence of the issues and were able to absorb the basics of pedagogy to support the distribution of the training content and spread awareness. Know-how gained through TTT will contribute to the advancement of knowledge in promoting sustainable maritime transport development as advanced by the IMO. It is the authors' strong belief that the way that the TTT course is designed, developed and delivered provides unique benefits for the participants and their countries.
\end{abstract}

\section{Keywords}

GHG Emissions, Capacity Building, Energy Efficiency, International Shipping, Developing Countries, Education and Training, Environmental Sustainability

\footnotetext{
${ }^{*}$ Corresponding author.
}

How to cite this paper: Baumler, R., Ölçer, A.I., Pazaver, A., Nakazawa, T., Baldauf, M., Moon, D. and Cole, C. (2014) Trainthe-Trainer Course on Energy Efficient Operation of Ships. American Journal of Climate Change, 3, 404-412. 


\section{Introduction}

Although seaborne transportation is considered environmentally sound compared to other transportation systems (Figure 1), the magnitude of shipping services multiplies the sources of air emission, which is presently under increased pressure.

This societal pressure and other environmental concerns along with high and volatile fuel prices have redrawn attention to energy efficiency as a solution to reduce GHG emissions and energy expenses [1]. This context prompted the industry and its international institution to respond. To curb GHG emissions and enhance energy efficiency, a wide range of diverse technologies and solutions have been put forward. Various technical, operational and commercial measures have been tested and implemented across the shipping industry. To name a few, weather routing, hull form optimisation, use of solar panels, kite and sails, real-time energy performance monitoring, LNG as a marine fuel, trim optimisation, onshore power supply, ballast water management, and engine load management. In short, energy efficiency during operation of ships has been recognised as a key tool to deal with the challenges associated with GHG emissions from international shipping.

In this wake of the Second IMO GHG study 2009 [1], the IMO accompany this process by adopting mandatory regulations to promote energy efficiency. These regulations form the first internationally binding instruments to control GHG emissions in the maritime industry.

This paper presents the development of the train-the-trainer course on energy efficient operation of ships developed under the partnership of IMO with KOICA (The Korea International Cooperation Agency) to support the implementation of these new regulations in the scope of the IMO mandate [2]; and to promote energy efficient operation of ships by presenting numerous solutions and case studies.

The course provides a common set of knowledge and skills to all participants in order to enable them to spread the acquired information in developing countries and to promote regulation implementation and good practices as requested by the MARPOL Annex VI regulatory framework.

The course assists developing countries in building their own capacity on energy efficient operation of ships and it raises awareness of the issue of GHG emissions from international shipping. On the whole, know-how gained will contribute to the advancement of knowledge in promoting sustainable maritime transport development and advance the goal of environmental and economic sustainability of shipping on the world's oceans.

The subsequent chapter justifies the course development and its promotion by the IMO. The next chapter explains the methodology behind the training programme developed as well as the contents of the programme. The developments containing future plans of the work are given in the fourth chapter. The paper is concluded in the last chapter.

\section{Justification of the Course Development}

Often invisible, shipping industry occupies the core of globalization and leads its developments [3]. In this

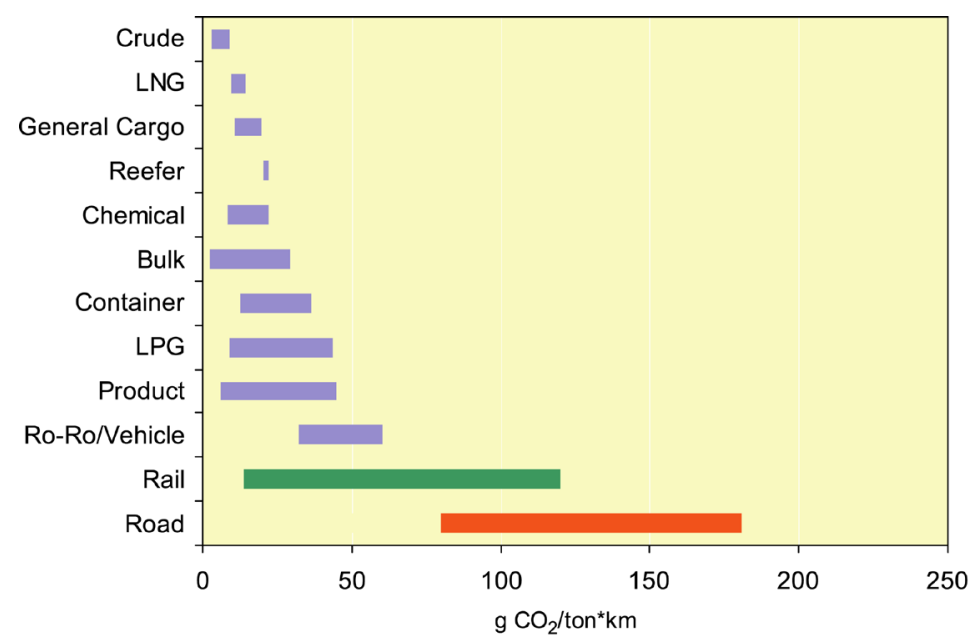

Figure 1. Typical ranges of $\mathrm{CO}_{2}$ efficiencies of ships compared with rail and road transport (Second IMO GHG study 2009). 
respect, the explosion of seaborne trade since 1970s (2.6 billion tons in 1970 and 9.1 billion tons in 2012) initiated the redistribution of the worldwide production system.

The magnitude, the reliability and the low cost of sea transport disperse and reshuffle the location of industrial centers as well as integrate the world economies as never before. "While the reorientation in global production and trade continues, with developing countries contributing larger shares to world output and trade, the performance of the global economy and merchandise trade in 2012 is a reminder of the high level of global economic integration and interdependence" [4].

The overwhelming presence of trade involves the acceleration of the development of transportation systems and particularly of maritime fleets representing long-distance and intercontinental trade. "The world fleet has more than doubled since 2001, reaching 1.63 billion deadweight tons in January 2013” [4].

In short, shipping materializes the world trade system and justifies the redistribution of production systems. Despite its benefits, shipping industry generates some negative externalities. Among them, the air pollution remains an important issue. The development of international regulation to address climate change places shipping under the spotlight because its total amount emissions are equivalent to a country like Germany.

In deed, the GHG emissions from shipping are not negligible (Table 1). "For the period 2007-2012, on average, shipping accounted for approximately $3.1 \%$ of annual global $\mathrm{CO}_{2}$ and approximately $2.8 \%$ of annual GHGs on a $\mathrm{CO}_{2} \mathrm{e}$ basis using 100-year global warming potential conversions from the AR5" [5]. Moreover, the expected world trade expansion risks to dramatically increase shipping related GHG emissions (Figure 2) in spite of technological development. "Maritime $\mathrm{CO}_{2}$ emissions are projected to increase significantly in the coming decades. Depending on future economic and energy developments, this study's BAU scenarios project an increase by $50 \%$ to $250 \%$ in the period to 2050 " [5].

While international shipping remains aside the main scope of the United Nation Framework Convention on Climate Change (UNFCCC), the pressure to address ships' emissions and particularly GHG increased during the last decade and engaged the IMO to tackle the issue of marine bunker fuels. The article 2.2 of the Kyoto Protocol

Table 1. Shipping emissions 2007-2013 (Third IMO GHG study 2014 presented in IMO paper MEPC 67/INF.3).

\begin{tabular}{|c|c|c|c|c|c|}
\hline \multicolumn{6}{|c|}{ Shipping $\mathrm{CO}_{2}$ emissions compared with global $\mathrm{CO}_{2}$ (values in million tonnes $\mathrm{CO}_{2}$ ) } \\
\hline Year & Global $\mathrm{CO}_{2}$ & Total shipping & $\%$ of global & International shipping & $\%$ of global \\
\hline 2007 & 31,409 & 1100 & $3.5 \%$ & 885 & $2.8 \%$ \\
\hline 2008 & 32,204 & 1135 & $3.5 \%$ & 921 & $2.9 \%$ \\
\hline 2009 & 32,047 & 978 & $3.1 \%$ & 855 & $2.7 \%$ \\
\hline 2010 & 33,612 & 915 & $2.7 \%$ & 771 & $2.3 \%$ \\
\hline 2011 & 34,723 & 1022 & $2.9 \%$ & 850 & $2.4 \%$ \\
\hline 2012 & 35,640 & 949 & $2.7 \%$ & 796 & $2.2 \%$ \\
\hline Average & 33,273 & 1016 & $3.1 \%$ & 846 & $2.6 \%$ \\
\hline \multicolumn{6}{|c|}{ Shipping GHGs (in $\mathrm{CO}_{2} \mathrm{e}$ ) compared with global GHGs (values in million tonnes $\mathrm{CO}_{2} \mathrm{e}$ ) } \\
\hline Year & Global $\mathrm{CO}_{2} \mathrm{e}$ & Total shipping & $\%$ of global & International shipping & $\%$ of global \\
\hline 2007 & 34,881 & 1121 & $3.2 \%$ & 903 & $2.6 \%$ \\
\hline 2008 & 35,677 & 1157 & $3.2 \%$ & 940 & $2.6 \%$ \\
\hline 2009 & 35,519 & 998 & $2.8 \%$ & 873 & $2.5 \%$ \\
\hline 2010 & 37,085 & 935 & $2.5 \%$ & 790 & $2.1 \%$ \\
\hline 2011 & 38,196 & 1045 & $2.7 \%$ & 871 & $2.3 \%$ \\
\hline 2012 & 39,113 & 972 & $2.5 \%$ & 816 & $2.1 \%$ \\
\hline Average & 36,745 & 1038 & $2.8 \%$ & 866 & $2.4 \%$ \\
\hline
\end{tabular}




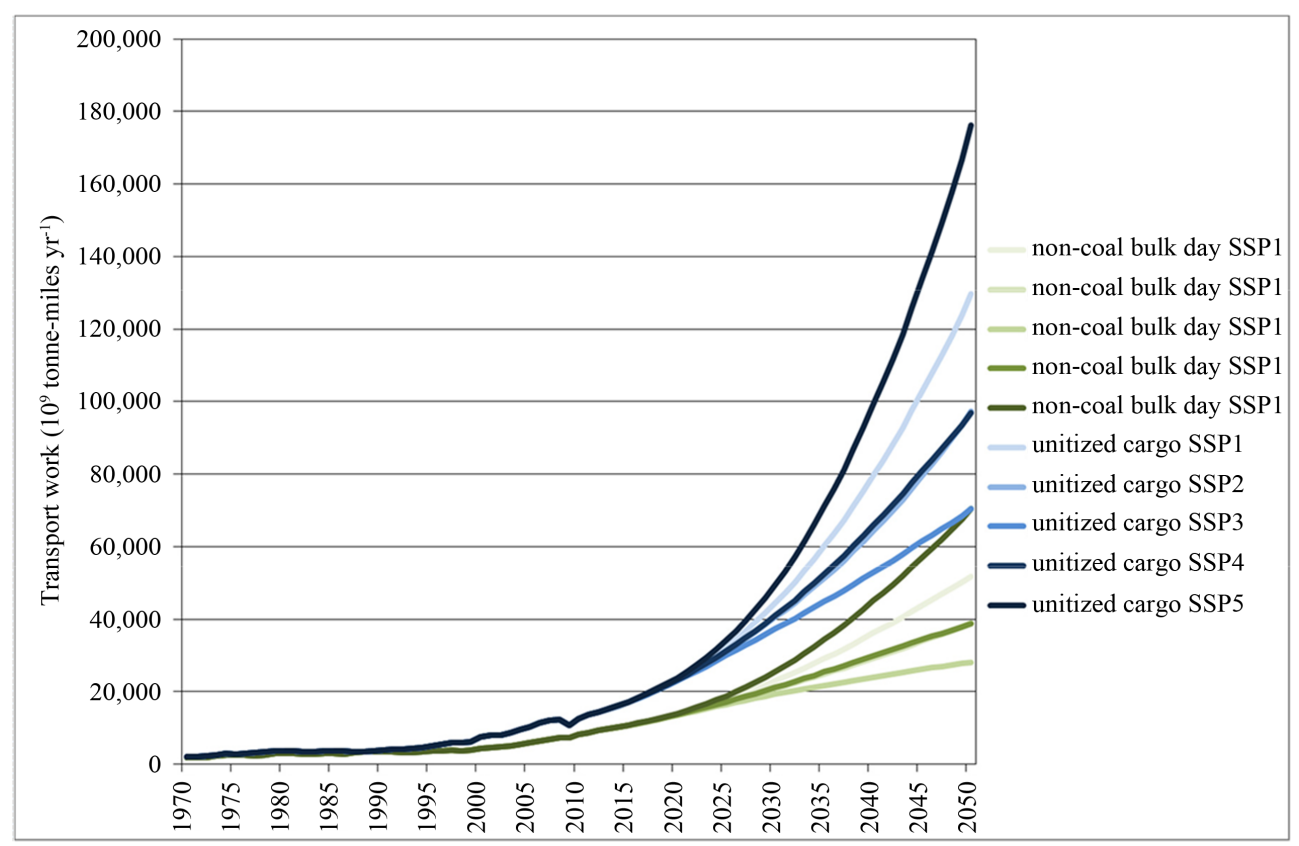

Figure 2. Projection of shipping increase by 2050 (Third IMO GHG study 2014 presented in IMO paper MEPC 67/INF.3). "The projections of demand for international maritime transport show a rapid increase in demand for unitized cargo transport, as it is strongly coupled to GDP and statistical analyses show no sign of demand saturation".

recalled the mission of the international specialized agencies dealing with transport to coordinate the efforts to reduce GHG emissions: "The Parties included in Annex I shall pursue limitation or reduction of emissions of greenhouse gases not controlled by the Montreal Protocol from aviation and marine bunker fuels, working through the International Civil Aviation Organization and the International Maritime Organization, respectively” (Kyoto Protocol, Article 2.2). In addition, since 1997, the Subsidiary Body for Scientific and Technical Advice (SBSTA) request the IMO and ICAO to provide reports on their relevant works to address GHG.

To participate in the world effort to curtail GHG emissions and demonstrate its proactive attitude, the IMO developed binding regulations in 2011, which began to enter into force on ships in 2013. Inserted in MARPOL Annex VI, the "Chapter 4-Regulations on energy efficiency for ships" emphasizes on the need to consider enhancement of design and operations of ships as well as promotes "technical co-operation and transfer of technology relating to the improvement of energy efficiency of ships" (Regulation 23).

The regulations (20 and 21) on ship design (Energy Efficiency Design Index-EEDI) propose a calendar of goals to reach without imposing solutions. The regulation (23) to enhance operations does not impose any reduction targets. The industry appreciates the present set of regulations because their freedom remains nearly unrestricted, and, in such an energy intensive industry, energy efficiency directly means cost cutting.

To support co-operation and technology transfer, the IMO spreads the present good practices in the world and particularly those related to ship operations because such practices are easily accessible and immediately applicable. In this context, the IMO used its training institution-The World Maritime University-competencies and expertise in dealing with international maritime administration to develop a dedicated course to present the measures to improve energy efficiency on ships.

\section{Methodology of the Train-the-Trainer Course}

In its mission to enhance "technical co-operation and transfer of technology", the Marine Environment Division (MED) of the IMO initiated the Train-the-Trainer (TTT) project on energy efficient operation of ships. This innovative project aimed to enhance capacity building in the field of energy efficient operation of ships.

The project supports the implementation of IMO regulations and dissemination of present available practices. The IMO publicized this project to the United Nations Framework on Convention on Climate Change particu- 
larly during the ad Hoc Working Group on the Durban Platform for Enhanced Action and the 18th Conference of Parties in 2012 [6] and its note to the 38th Session of the Subsidiary Body for Scientific and Technological Advice (SBTA 38) in 2013 [7].

\subsection{The Project Technical Background}

The TTT project combines two ideas:

- Development of supporting documents to assist the assimilation and the practices related to the new regulations. A dedicated training package to support conventions has already been successfully implemented by the IMO to promote the International Convention for the Control and Management of Ships' Ballast Water and Sediments, 2004.

- Training of a pool of instructors able to distribute this knowledge. Instead of sending experts from one side of the world to the other, the idea promotes the development of local expertise. Each participant in the TTT benefits from technical training to gain knowledge and pedagogic advice to enhance training abilities and develop confidence. It is expected that these local specialists will introduce and present the issues in their respective local contexts. This specific training methodology supports another major maritime convention. The Maritime Labour Convention, 2006 is promoted by the International Training Centre of the International Labour Organization (ITCILO) through two-week train-the-trainer workshops in Turin-Italy.

\subsection{The Two-Phase of the Project}

Taken together, these ideas constitute a two-phase project: 1) development of training package covering the issue complemented with a trainer manual and 2) organization of two TTT sessions.

The TTT solution to enhance capacity building was preferred for the following reasons:

- Building a pool of IMO identified trainers suitable to disseminate knowledge in their respective countries and regions;

- Enhancing the overall efficiency of the awareness programme by expanding the number of instructors able to adapt to local constraints and contexts;

- Engaging the participants through an active learning system;

- Establishing a set of reference documents and generic presentations.

Completed late 2012, and under continuous review, the training package provides comprehensive and easily accessible information on the topic (technical modules including also related sample cases studies and even guidance on the implementation of simulation exercises). In addition, a specific pedagogical support document was developed to assist dissemination by the pool of trainers (pedagogic module).

The determination of the technical content was mutually agreed between IMO and WMU after formal consultation with shipping stakeholders:

- One stakeholders meeting involving State representatives and IMO observers occurred in London in September 2012. The meeting was organized to collect comments and data from various shipping stakeholders;

- Additional meetings were held at the IMO and WMU in September 2012. Their purposes were to ensure mutual understanding on content and objectives;

- One technical review meeting was held at the IMO in November 2012.

\subsection{Building a Pool of Experts}

The TTT course on energy efficient operation of ships was delivered at the World Maritime University in Malmö-Sweden on two occasions (February and May 2013). As the main objective of the project was to establish a pool of instructors, external participants were nominated by their administrations, following a call made by the IMO and managed by the WMU. The selection process aimed to encompass as many nationalities as possible. Each session was a mix of external participants and voluntary WMU students. In order to enhance group interaction, the training was restricted to 20 participants; however, an additional student was accepted during the first session. Selected participants included 21 WMU MSc students as well as 20 external participants. All together, they represented 32 different countries. Despite the willingness to promote gender diversity, only one third of the participants were women. The participants represented their administrations or worked with them: maritime administrations (70\% of participants), maritime education and training institutions (20\%) and the pri- 
vate sector, including independent consultants (10\%).

\subsection{Content and Context}

In order to describe the areas that may impact energy efficient ship operations, the technical package is divided into five content modules. Moving from general to specific, the package begins with broad principles and concludes with the Ship Energy Efficient Management Plan (SEEMP), which represents a key component of the MARPOL Annex VI Chapter 4 regulations on energy efficiency. Each module has a specific focus, which can be taught independently according to the audience.

Module 1 constitutes the introductory section, which identifies the principles and the response tools developed by the international community to address air emissions. A short introduction highlights the emergence of pollution through the socioeconomic changes and energy choices made during the early stages of the industrial revolution. The distinction between local air pollutants and global effects of air composition alteration is established and responses are briefly highlighted. The final section of the module introduces the issue of greenhouse gas in shipping and presents the IMO policies developed to address the issue.

Module 2 emphasizes company management responsibility to enhance energy efficient operations by defining appropriate policies. The link between energy savings and profit making is established as the major incentive to invest in air emission control and benefit from industry support. Another incentive to promote energy management exists through the corporate social responsibility concept. However, the text recalls restrictions, often imposed by the various contracts regulating shipping business-i.e. some contract types create split incentives. The last part of the module details the elements to consider when developing a company energy efficiency policy.

Module 3 is the only module, which includes port related aspects. It touches upon port operations, port stay and its impact as well as just-in-time arrival/departure and improved cargo handling at ports. As a separate chapter onshore power supply is explained. Green port initiatives are also covered in this module. A detailed case study is provided for the impact of port time changes on operating costs and GHG emission figures.

Module 4 includes the chapters of Voyage Management, Engine Load Management, System Planning for Energy Efficiency and Trim Optimisation. The first chapter focuses on the Just in Time concept, virtual arrival, weather routing, energy efficient ship operation in coastal areas and harbours, and E-Navigation with a sample of an integrated simulation-based exercise [8]. The second chapter mainly deals with load management related aspects for main and auxiliary engines. The subsequent chapter looks into ballast water management, electrical load reduction, boiler operation and pitch optimisation. The final chapter is dedicated solely to trim optimisation. The various chapters were enhanced with illustrative case studies.

Module 5 deals with Energy Efficiency Management Systems, focusing on two aspects: principle and management of the Ship Energy Efficiency Management Plan (SEEMP) and practice and review of a management system. The SEEMP was covered in this module because it came into force on the first of January 2013 as an amendment to MARPOL Annex VI, and is mandatory for all ships.

\subsection{TTT Course Delivery}

Five successive technical content modules and a pedagogic module were distributed. The documents provided to participants included two textbooks (technical and pedagogical) as well as numerous IMO and other relevant publications. An electronic version of all documents including the training presentations was provided during the closing ceremony.

An informal discussion session was held on the first morning in order to establish the participants' existing knowledge, experience and perspectives in relation to the topic and to provide a foundation for the delivery of the content modules. Considering the diversity of the audience, this informal discussion aimed to capture trainees' attention by discussing each participant's country experience addressing air emissions as well as identifying good practices.

Technical and pedagogic modules were delivered by subject matter experts (SMEs). The technical and pedagogical aspects covered 12 hours each. The final day was dedicated to assessing the participants and ensuring their technical understanding and teaching abilities.

The technical modules aimed to provide the future instructors with a foundation of knowledge to use and modify as per their convenience. Not intended to be reiterated intact, the modules must be contextualized to the 
trainers' local conditions of delivery in terms of time, audience profile, national and institutional constraints and available support. As such, participants were encouraged through question and answer sessions, group discussions and active learning tasks to interpret the information in consideration of these factors.

As one of the dual objectives of the course was to prepare the participants to deliver the information learned, a supplementary pedagogical element was included. While the technical content is intended to support regional and national seminars delivered by the pool of instructors, the pedagogic module is distributed only to the TTT participants. This section was aimed at providing the participants with an awareness of some of the theories and practicalities underlying instructional design and training methodology in order to enable them to effectively develop, present and manage their own training programs. The content of the pedagogic module included an introduction to adult learning principles, learning styles, instructional approaches and presentation skills and strategies. This was intended to serve as a refresher course for those participants with teaching and training experience and expertise and as an introduction to teaching and learning approaches for those with little or no previous experience as trainers. The pedagogic aspect involved some theory, but focused primarily on the application of learning theory to practical teaching and training situations. The participants were provided with numerous opportunities for group discussions and tasks as a means of engaging with the content.

To engage and motivate the participants, a final assessment task to be completed on the final day of the course was set on day one. The threefold need to keep trainees attention high, to confirm their knowledge acquisition and to observe their training skills justified this assignment.

Participants were asked to work in groups over the course of the week in order to prepare and deliver a presentation summarizing the key points of the five technical content modules. The presentation task was designed to assess whether the participants had met the learning objectives specified at the beginning of each module. At the same time, the preparation of the presentation provided a unique opportunity for the participants to reflect on and discuss the subject matter in a collaborative setting, engaging multiple perspectives on what was learned. Participants were encouraged to interpret the information learned in the modules based on their own experiences and to apply the new knowledge to their own needs, backgrounds and interests (and those of their countries and institutions). It was thought that this would enhance both their understanding and retention of the information. Finally, the presentation task provided an opportunity for the participants to practice and gain confidence in their newly acquired skills in preparation for their eventual role as instructor.

The presentations were delivered in front of an audience consisting of the subject matter experts and other participant groups. Following each presentation, participants received immediate feedback from the subject matter experts as well as from their colleagues. Strengths and weaknesses with regard to the accuracy of the content and the effectiveness of the delivery were discussed amongst all participants and suggestions for improvement were given. Participants were able to review their own performances as the presentations were recorded and subsequently emailed to the participants along with more detailed individual feedback.

\subsection{Feedback from Participants}

As is usual practice in such IMO and WMU courses, the co-ordinator collected the feedback forms to establish a quantitative analysis. In addition to this written feedback by participants, trainers discussed and assessed the efficiency of the course.

In general, participants strongly supported the course and praised its quality. The TTT formula, providing a blend between teaching and technical skills, was considered relevant and engaging. The teaching documents and support were appreciated.

Interaction with trainers and between participants constituted the strength of the programme. Each session, voluntarily limited to 20 participants, was again divided into four groups. The large diversity of countries represented offered a unique opportunity for many participants to compare their views and practices with others. This demonstrated to participants the variety of approaches, constraints and solutions involved in tackling the issue. Encouragement to absorb the knowledge but to adjust their at-home deliveries to their contexts was justified by the objective to support local needs. In this respect, originally developed in English, the translation of the training package into other UN languages could help the dissemination.

The presence of WMU students did not represent any disturbance because the students possess the same background as the external participants. Delivering the training at WMU offered the possibility to instruct 41 trainers instead of 20 as per budget constraints. 
Some participants expressed their willingness to see an extended program. They suggested that additional time would allow for more and extended debates and exchanges particularly during group work sessions as well as a better assimilation of the vast information presented. In this respect, the ILO-ITC course on the Maritime Labour Convention, 2006 is a two-week training program.

The considerable interaction with the participants was also a unique opportunity to assess the reality of training needs in the field of air emissions and climate change. It soon became obvious that additional training was needed in order to enhance awareness on the air emission control topic and eradicate misconceptions.

In July 2013, a meeting at the IMO concluded the project. Its purpose was to identify the way forward. The modularity of the training package justifies the addition of new modules covering related topics such as:

- Concept of sustainable development and its translation to the maritime field;

- MARPOL Annex VI: general knowledge;

- Emission Control Areas/SOx and NOx policies and mitigation technologies;

- Energy Efficiency Design Index principles and developments.

Other topics related to the issue have been identified but the above constitute a priority and the WMU has already produced proposals to cover them.

\section{Developments}

Since the end of the project for the WMU, the training course remains alive with several meetings held in countries (with or without IMO support) as well as regional training courses.

To name just a few of the courses that recently occurred using the developed material: Saudi Arabia in November 2013, India in April and September 2014, and Turkey November 2014. One course in India targeted the Shipping Corporation of India (a major shipping actor of the country), while the second course was a regional meeting led by the IMO.

Moreover, the course developed during the project is delivered (in full or partially) on a yearly basis to WMU students and during Professional Development Courses held at Malmö.

In addition, the TTT project serves at WMU to identify new trends of teaching, research and partnership. This project strengthens the involvement of the WMU in energy management issues as well as builds a cooperation among the teaching staff and external partners on the issue. Today, the issues of GHG control and energy management, which were minor topics, are expanding in the curriculum of the University. In this respect, the WMU and the Lloyds Maritime Academy jointly developed in 2014 a partnership for a PG Diploma in Maritime Energy Management. Many project research proposals are in the pipeline and it is expected that 2016 or 2017 will see the creating of a new master programme dedicated to Maritime Energy Management in WMU. Any additional information on this programme and its developments can be obtained by contacting Dr. Aykut Ölçer or Dr Raphaël Baumler at WMU.

\section{Conclusions}

There is an urgent need to respond to global environmental challenges, in particular GHG emissions from international shipping. A wide range of innovative technologies and solutions has already been put forward across the shipping industry. Those with practical applications to enhance energy efficient operation of ships have become the motivation for a train-the-trainer (TTT) course. Supported by the IMO with KOICA (The Korea International Cooperation Agency), such a course was developed by WMU and delivered to participants from 32 countries. They were all trained with regard to technical and pedagogical aspects to become trainers on energy efficient ship operations in their home countries. The development, methodology, context and delivery of this course are explained thoroughly in this paper. The following can be concluded from the development and delivery of this course:

- It will help developing countries build their own capacity on energy efficient operation of ships.

- It will raise awareness of issues related to GHG emissions from international shipping in developing countries.

- The work can be considered as a good example of collaboration between UN agencies. The university provides research, project development and teaches, backs an agenda adopted by the IMO and the UN.

- Relevant to WMU students, parts of the training will be incorporated into the curriculum and will support 
new trends under development.

- The survey conducted with the participants revealed other areas that need to be addressed.

- It will contribute to sustainable maritime transport development through capacity building and awareness raising.

Know-how gained will contribute to the advancement of knowledge in promoting sustainable maritime transport development as advanced by the IMO. It is the authors' strong belief that the way that the TTT course is designed, developed and delivered provides unique benefits for the participants and their countries.

Based on the above-mentioned achievements, this success story can be expanded to cover issues related to air pollutants resulting from seaborne transportation, which will form a complete training package supporting IMO objectives.

\section{Acknowledgements}

This article resulted from a train-the-trainer project on energy efficient operation of ships funded by the partnership of IMO with KOICA. The authors are grateful for this and they are thankful to Dr. Zabi Bazari and Capt. Colin Thomas for their contributions to the development of the textbook and presentations of the project and the delivery. They also appreciate the support of Dr. Jose Matheickal, Dr. Edmund Hughes, Capt. Dandu Pughiuc from the IMO secretariat throughout the project.

\section{References}

[1] International Maritime Organization (2009) Second IMO Greenhouse Gas Study 2009. IMO, London.

[2] International Maritime Organization (2006) Resolution A. 986(24): The Importance and Funding of Technical Co-Operation as a Means to Support the United Nations Millennium Declaration and the Millennium Development Goals. IMO, London.

[3] Levinson, M. (2006) The Box: How the Shipping Container Made the World Smaller and the World Economy Bigger. Princeton University Press, Princeton.

[4] United Nations Conference on trade and Development (2013) The Review of Maritime Transport 2013. UNCTAD/ RMT/2013, United Nations Publication.

[5] International Maritime Organization (2014) Third IMO Greenhouse Gas Study 2014. IMO, London.

[6] International Maritime Organization (2012) IMO’s Work to Address GHG Emissions Form International Shipping. Meeting of the ad Hoc Working Group on the Durban Platform for Enhanced Action, Bangkok, 30 August-5 September 2012.

[7] International Maritime Organization (2013) Update on IMO’s Work to Address Emissions from Fuel Used for International Shipping. 38th Session of SBSTA, Bonn, 3-14 June 2013.

[8] Baldauf, M., Baumler, R., Ölçer, A., Nakazawa, T., Benedict, K., Fischer, S. and Schaub, M. (2013) Energy-Efficient Ship Operation-Training Requirements and Challenges. International Journal on Marine Navigation and Safety of Sea Transportation, 7, 283-290. 
Scientific Research Publishing (SCIRP) is one of the largest Open Access journal publishers. It is currently publishing more than 200 open access, online, peer-reviewed journals covering a wide range of academic disciplines. SCIRP serves the worldwide academic communities and contributes to the progress and application of science with its publication.

Other selected journals from SCIRP are listed as below. Submit your manuscript to us via either submit@scirp.org or Online Submission Portal.
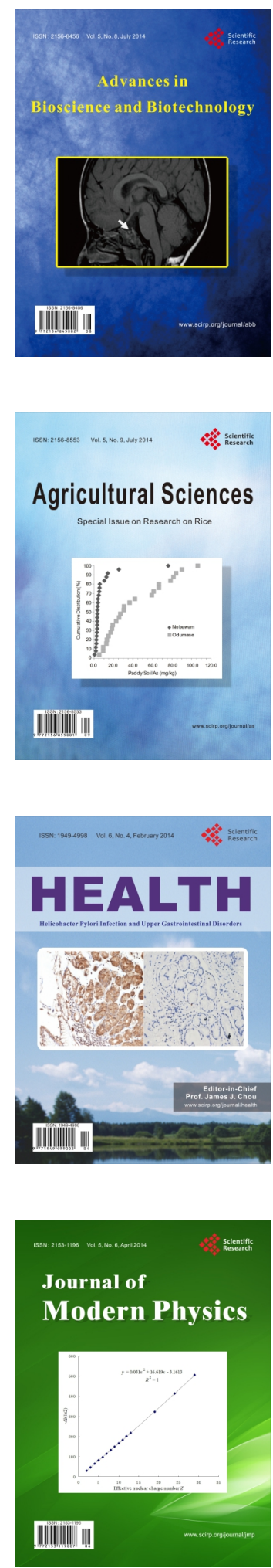
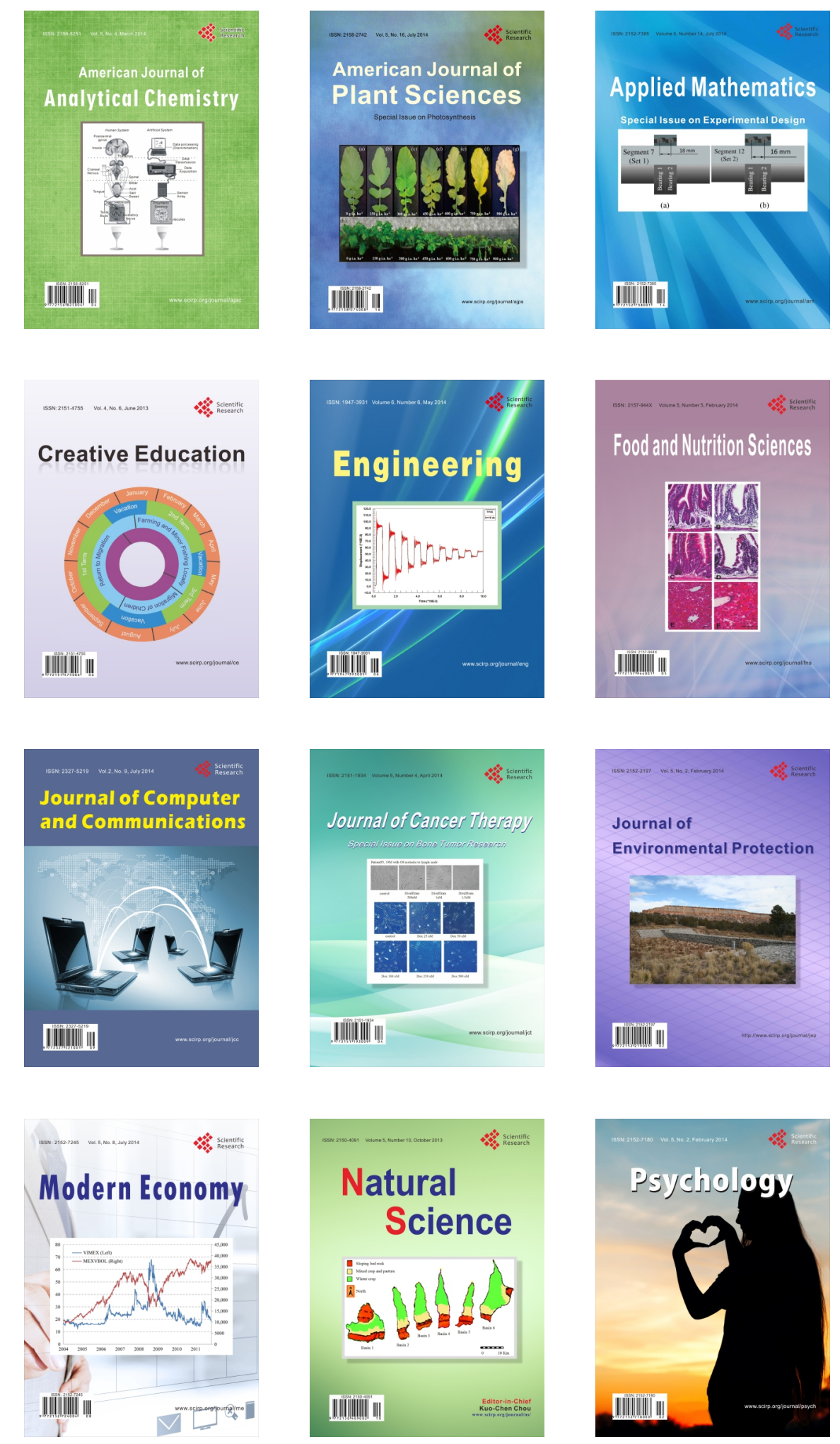